AperTO - Archivio Istituzionale Open Access dell'Università di Torino

\begin{abstract}
Allogeneic transplantation improves the overall and progression-free survival of Hodgkin lymphoma patients relapsing after autologous transplantation: a retrospective study based on the time of HLA typing and donor availability.
\end{abstract}

This is the author's manuscript

Original Citation:

Availability:

This version is available http://hdl.handle.net/2318/81941

since 2017-10-19T12:16:12Z

Terms of use:

Open Access

Anyone can freely access the full text of works made available as "Open Access". Works made available under a Creative Commons license can be used according to the terms and conditions of said license. Use of all other works requires consent of the right holder (author or publisher) if not exempted from copyright protection by the applicable law. 


\section{IIIS AperTO}

UNIVERSITÀ

DEGLI STUDI

DI TORINO

This is the author's final version of the contribution published as:

Barbara Sarina, Luca Castagna, Lucia Farina, Francesca Patriarca, Fabio Benedetti, Angelo M. Carella, Michele Falda, Stefano Guidi, Fabio Ciceri, Alessandro Bonini, Samantha Ferrari, Michele Malagola, Enrico Morello, Giuseppe Milone, Benedetto Bruno, Nicola Mordini, Simonetta Viviani, Alessandro Levis, Laura Giordano, Armando Santoro, Paolo Corradini and for Gruppo Italiano Trapianto di Midollo Osseo

Paper: Allogeneic transplantation improves the overall and progression-free survival of Hodgkin lymphoma patients relapsing after autologous transplantation: a retrospective study based on the time of HLA typing and donor availability BLOOD, 115 (18), 2010, pp: 3671-3677

DOI: 10.1182/blood-2009-12-253856

The publisher's version is available at:

https://doi.org/10.1182/blood-2009-12-253856

When citing, please refer to the published version.

Link to this full text:

http://hdl.handle.net/2318/81941 


\title{
Allogeneic transplantation improves the overall and progression-free survival of Hodgkin lymphoma patients relapsing after autologous transplantation: a retrospective study based on the time of HLA typing and donor availability
}

\author{
Barbara Sarina, Luca Castagna, Lucia Farina, Francesca Patriarca, Fabio Benedetti, Angelo M. Carella, \\ Michele Falda, Stefano Guidi, Fabio Ciceri, Alessandro Bonini, Samantha Ferrari, Michele Malagola, \\ Enrico Morello, Giuseppe Milone, Benedetto Bruno, Nicola Mordini, Simonetta Viviani, Alessandro \\ Levis, Laura Giordano, Armando Santoro, Paolo Corradini , and Gruppo Italiano Trapianto di Midollo \\ Osseo
}

\begin{abstract}
Hodgkin lymphoma relapsing after autologous transplantation (autoSCT) has a dismal outcome. Allogeneic transplantation (alloSCT) using reduced intensity conditioning (RIC) is a salvage option, but its effectiveness is still unclear. To evaluate the role of RIC alloSCT, we designed a retrospective study based on the commitment of attending physicians to perform a salvage alloSCT; thus, only Hodgkin lymphoma patients having human leukocyte antigen-typing immediately after the failed autoSCT were included. Of 185 patients, 122 found an identical sibling (55\%), a matched unrelated (32\%) or a haploidentical sibling (13\%) donor; 63 patients did not find any donor. Clinical features of both groups did not differ. Two-year progression-free (PFS) and overall survival (OS) were better in the donor group (39.3\% vs $14.2 \%$, and $66 \%$ vs $42 \%$, respectively, $P<.001$ ) with a median follow-up of 48 months. In multivariable analysis, having a donor was significant for better PFS and OS $(P<.001)$. Patients allografted in complete remission showed a better PFS and OS. This is the largest study comparing RIC alloSCT versus conventional treatment after a failed autoSCT, indicating a survival benefit for patients having a donor.
\end{abstract}

\section{Introduction}

Hodgkin lymphoma $(\mathrm{HL})$ is considered a curable disease in approximately $75 \%$ of the cases. Approximately $50 \%$ of patients relapsing after the first-line chemotherapy can be rescued by an autologous stem cell transplantation (autoSCT), whereas the others, which account for approximately $10 \%$ to $15 \%$ of the overall population, have a very poor prognosis. ${ }^{1-3}$ For these patients with refractory disease or relapsing after an autoSCT, salvage chemo-radiotherapy produces only short-lasting responses, and their median overall survival ranges between 8 and 38 months. ${ }^{4-9}$

Allogeneic stem cell transplantation (alloSCT) has been used in relapsed HL patients with controversial results. Myeloablative regimens carried an unacceptably high nonrelapse mortality (NRM), whereas reduced intensity conditioning (RIC) showed a promising decrease in NRM rates. ${ }^{10-12}$ Nevertheless, with both approaches, long-term progression-free survival curves did not exceed $20 \%$ to $25 \%$ in most of the studies. ${ }^{12-17}$ Moreover, data regarding the responses to donor lymphocyte infusions (DLIs) are conflicting, thus questioning the existence of the postulated "graft-versus-HL effect." ${ }^{13-18}$ To date, only 1 retrospective study suggested the superiority of RIC alloSCT over conventional "non-SCT" therapies in patients relapsing after an autoSCT. ${ }^{19}$

To evaluate the role of RIC alloSCT as a realistic salvage option in the clinical setting, we performed a retrospective analysis on patients relapsing after an autoSCT. Italian hematology centers participating in 
prospective national trials of alloSCT in lymphomas were requested to review all their HL cases relapsing after an autoSCT. Primary refractory patients were not included. From all patients failing an autoSCT, only those having the human leukocyte antigen (HLA) typing done within 30 days after the post-SCT relapse were selected. This was done to have a homogeneous population, including only patients for whom the attending physician was really motivated to proceed to a salvage alloSCT. Patients were then divided into 2 groups based on the donor availability. The study aim was to elucidate whether having a donor might be beneficial for the outcome of HL patients relapsing after an autoSCT.

\section{Methods}

\section{Patient characteristics}

Patients' characteristics are reported in Table 1. Considering the time period of the study (1999-2008) and the participating centers, 710 patients underwent autoSCT for $\mathrm{HL}$ and 329 relapsed after autografting; 185 fulfilled the study criteria and were enrolled in our retrospective study. A total of 107 of 329 patients underwent alloSCT. It must be kept in mind that few patients included in the study relapsed during the indicated time period but received their autoSCT before 1999. The data on $185 \mathrm{HL}$ patients treated from 1999 to 2008 were retrospectively collected in 15 Italian Centers under a protocol approved by all institutions participating in this study. All these patients were relapsed after an autoSCT and had their HLA typing done within the first 30 days after relapse. To verify that the selected patients fulfilled the aforementioned criteria and to exclude any selection bias, we proceeded as follows: (1) a synopsis of the study was sent to all centers; after their agreement to join the study, they received a letter explaining how to proceed and how to collect the data required in a specific patient form; (2) each center designated an investigator in charge of the study; (3) they reviewed all the patients relapsing after autoSCT in the time period specified by the study; after doing so, they looked at the patients having an HLA typing and the study included only those doing it within 30 days from the relapse date; and (4) the patient forms coming back from all centers were reviewed by a statistician and a senior hematologist; and, when required, specific queries were sent to each center. Primary refractory patients, defined as patients who never experienced a disease response after first-line chemotherapy or autoSCT, were excluded from this study. Disease response was evaluated through clinical examination, blood chemistry, bone marrow biopsy, and imaging techniques (total body computed tomography scan and, when available, positron emission tomography).

Table 1. Patient characteristics

\begin{tabular}{|c|c|c|c|c|}
\hline & Total, no. (column \%) & Donor, no. (row \%) & No donor, no. (row \%) & $P$ \\
\hline All & $185(100)$ & $122(65.9)$ & $63(34.1)$ & \\
\hline$A g \theta, y[$ mean $(S D)]$ & $31.9(9.5)$ & $31.0(9.7)$ & $33.6(8.8)$ & .079 \\
\hline Sex & & & & .261 \\
\hline Male & $116(62.7)$ & $80(65.6)$ & $36(57.1)$ & \\
\hline Female & $69(37.3)$ & $42(34.4)$ & $27(42.9)$ & \\
\hline Time from autoSCT to relapse & & & & .411 \\
\hline 12 mo or less & $134(72.4)$ & $86(70.5)$ & $48(76.2)$ & \\
\hline More than 12 mo & $51(27.6)$ & $36(29.5)$ & $15(23.8)$ & \\
\hline Histology* & & & & .196 \\
\hline Nodular sclerosis & $137(83.0)$ & $91(85.9)$ & $46(78.0)$ & \\
\hline Other & $28(17.0)$ & $15(14.1)$ & $13(22.0)$ & \\
\hline
\end{tabular}

autoSCT indicates autologous transplantation

'The sum does not add to the total because of missing data. 


\section{Patient characteristics}

A total of 122 patients (66\%) had a suitable donor, whereas 63 patients (34\%) had not and were treated according to the common policy of each center, which consisted of salvage chemotherapy or radiotherapy in all the cases. The type of chemotherapy used in both the no-donor and donor groups was not significantly different and included: DHAP (dexamethasone, cisplatin, ara-C), IGEV (methylprednisolone, ifosfamide, gemcitabine, vinorelbine), or EPOCH (prednisone, etoposide, adriamycin, cyclophosphamide, vincristine). Mean age, sex, time from autoSCT to relapse ( $\leq 12$ vs $>12$ months), and histology (nodular sclerosis vs others) did not differ between the 2 groups.

A total of 104 of 122 patients with a donor (85\%) were actually allografted. Eighteen of 122 patients (15\%) did not receive the planned alloSCT; therefore, they were excluded in the analysis of outcome restricted to allografted patients, but they were included in all the "donor versus no-donor" analyses. Causes for not receiving alloSCT were: 10 cases of disease progression, 5 patient refusal, and 3 physician decision. Fiftyseven of the allografted patients (55\%) had an HLA identical sibling donor, 33 patients (32\%) had an HLAmatched unrelated donor, and 14 patients $(13 \%)$ had a haploidentical sibling donor. For unrelated donors, matching for HLA-A, HLA-B, and HLA-DRB1 loci was required by the Italian Registry. Ninety patients (86\%) received peripheral stem cells, 13 (13\%) bone marrow, and $1(1 \%)$ peripheral stem cells plus bone marrow. Before alloSCT, 21 of 104 (20\%) were in complete remission (CR), 46 of 104 (45\%) were in partial remission (PR), and 36 of 104 (35\%) had progressive disease (PD) or stable disease (SD). The great majority of RIC regimens consisted of fludarabine and cyclophosphamide combined with other drugs, mostly thiotepa or melphalan or busulfan ${ }^{15,20,21}$ (Table 2). Unrelated and haploidentical donors received T-cell depletion with antithymocyte globulin or alemtuzumab. Diagnosis and clinical grading of acute and chronic graft-versushost disease (GVHD) were performed using the international standard criteria. $^{22,23}$

\section{Table 2. Conditioning regimens}

\begin{tabular}{|c|c|}
\hline Conditioning regimen & $\begin{array}{l}\text { No. of } \\
\text { patients }\end{array}$ \\
\hline Fludarabine $\left(90 \mathrm{mg} / \mathrm{m}^{2}\right)+$ melphalan $\left(100-140 \mathrm{mg} / \mathrm{m}^{2}\right) \pm$ ATG & 15 \\
\hline Thiotepa $(10 \mathrm{mg} / \mathrm{kg})+$ cyclophosphamide $(100 \mathrm{mg} / \mathrm{kg}) \pm$ ATG & 11 \\
\hline $\begin{array}{l}\text { Fludarabine }\left(60 \mathrm{mg} / \mathrm{m}^{2}\right)+\text { cyclophosphamide }(60 \\
\mathrm{mg} / \mathrm{kg})+ \text { thiotepa }(10 \mathrm{mg} / \mathrm{kg})\end{array}$ & 49 \\
\hline Fludarabine $\left(150 \mathrm{mg} / \mathrm{m}^{2}\right)+$ busulfan $(8 \mathrm{mg} / \mathrm{kg})$ & 2 \\
\hline $\begin{array}{l}\text { Thiotepa (5 mg/kg) + cyclophosphamide (100 } \\
\left.\text { mg/kg) + melphalan (70 } \mathrm{mg} / \mathrm{m}^{2}\right)+ \text { ATG or alemtuzumab }\end{array}$ & 6 \\
\hline $\begin{array}{l}\text { Fludarabine }\left(120 \mathrm{mg} / \mathrm{m}^{2}\right)+\text { cyclophosphamide (60 } \\
\mathrm{mg} / \mathrm{kg})+ \text { thiotepa }(10 \mathrm{mg} / \mathrm{kg})+\text { alemtuzumab + TBI } 2 \text { Gy }\end{array}$ & 6 \\
\hline Fludarabine $\left(120 \mathrm{mg} / \mathrm{m}^{2}\right)+$ cyclophosphamide $\left(900 \mathrm{mg} / \mathrm{m}^{2}\right)$ & 11 \\
\hline Fludarabine $\left(90 \mathrm{mg} / \mathrm{m}^{2}\right)+\mathrm{TBI} 2 \mathrm{~Gy}$ & 4 \\
\hline
\end{tabular}
donors.

ATG or alemtuzumab has been used in matched-unrelated or haploidentical

ATG indicates antithymocyte globulin; and TBI, total body irradiation.

\section{Statistical analysis}

Two types of analysis have been performed: the first one was the so-called "donor versus no-donor" analysis to compare the outcomes of patients based on the availability of a donor; the second one was the 
analysis limited to allografted patients to assess the outcome of HL patients receiving RIC allograft. The starting point of our analysis was the day of relapse after autoSCT for the comparison between the donor and no-donor groups and the day of alloSCT for the analysis restricted to allografted patients. Progressionfree survival (PFS) and overall survival (OS) were defined according to the European Blood and Marrow Transplantation (EBMT) criteria for survival analysis. ${ }^{24}$ The NRM was defined as death from any cause other than $\mathrm{HL}$ progression. Associations with clinical characteristics were compared by $\chi^{2}$ for categorical data, and the $t$ test was used to compare continuous variables.

Survival analysis was performed by plotting survival curves by the Kaplan-Meier method. Patients were stratified according to the main available HL features, and groups were compared by the log-rank test. Statistically significant variables in univariate analysis were tested using multivariable Cox proportional hazard regression models, and hazard ratios (HR) with 95\% confidence intervals (Cls) were calculated. Cumulative incidences were analyzed by the Gray method. ${ }^{25} \mathrm{~A} P$ value less than .05 was considered to be the limit of statistical significance. All statistical analyses were performed using R-package.

\section{Results}

\section{Donor versus no-donor analysis}

\section{Disease response and survival curves.}

The median follow-up for all the patients was 47.9 months (range, 0.1-143 months). CR to salvage therapy was assessed in the donor (20\%) and no donor (27.6\%) groups, and the difference was not statistically significant, indicating that the groups were not unbalanced. At the last follow-up, 45 of 122 patients (37\%) of the donor group and 9 of 63 patients (14\%) of the no-donor group were in CR. Overall, 123 of 185 (66\%) patients progressed or relapsed after therapy. The median PFS and OS for all the patients were 15 and 29 months, respectively. PFS and OS of chemosensitive (CR and PR) versus chemorefractory (SD and PD) patients were analyzed. Not surprisingly, we found a significant advantage in PFS (at 2 years: 46.6 vs 5.3, $P$ $>.001$ ) and OS (at 2 years: 78.1 vs 27.5, $P>.001$ ) for chemosensitive patients. Two- and 4-year PFS were $39 \%$ and $26 \%$ in the donor group and $14 \%$ and $11 \%$ in the no-donor group $(P<.001)$, respectively (Figure 1A). Two- and 4 -year OS were $66 \%$ and $43 \%$ in the donor group and $42 \%$ and $15 \%$ in the no-donor group ( $P$ $<.001$ ), respectively (Figure 1B). 


\section{A PFS}

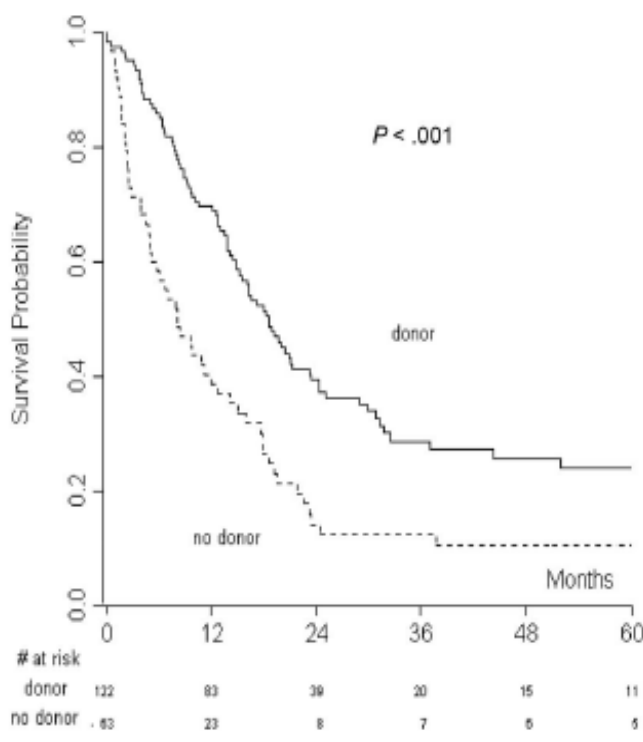

B os

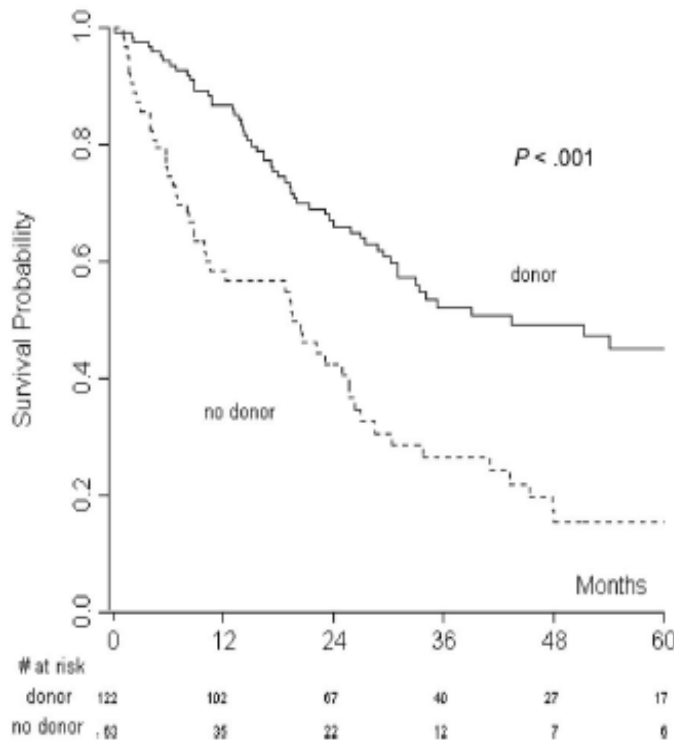

Figure 1. The donor versus no-donor analysis had the day of relapse after autologous transplantation as the starting point. (A) Progression-free survival (PFS) and (B) overall survival (OS) of the donor versus no-donor group.

Sex, histology, time from autoSCT to relapse, and the availability of a donor were analyzed in univariate analysis (Table 3). PFS and OS were significantly influenced by the availability of a donor $(P<.001)$, as well as the time from autoSCT to relapse (PFS, $P=.019$; OS, $P=.010$ ). Multivariable analysis demonstrated a significant correlation of both the factors with OS and PFS $(P<.001, P<.001$, for no-donor vs donor and $P=$ $.007, P=.023$ for $\leq 12$ vs $>12$ months from autoSCT to relapse). Patients without a donor had an HR of death of 2.47 ( $95 \% \mathrm{Cl}, 1.68-3.64$; Table 4) and an HR of progression/relapse of 1.94 (95\% Cl, 1.38-2.73).

Table 3. Univariate analysis

\begin{tabular}{|c|c|c|c|c|}
\hline \multirow[b]{2}{*}{ Classification } & \multicolumn{2}{|l|}{ PFS } & \multicolumn{2}{|l|}{ OS } \\
\hline & No. $(\%)$ of events (2-y survival) & $P(\log -$ rank $)$ & No. $(\%)$ of events (2-y survival) & $P$ (log-rank) \\
\hline All & $140(30.7)$ & & $105(58.0)$ & \\
\hline Intention to treatment & & $<.001$ & & $<.001$ \\
\hline Donor & $85(39.3)$ & & $56(66.0)$ & \\
\hline No donor & $55(14.2)$ & & $49(42.4)$ & \\
\hline Time from autoSCT to relapse & & .019 & & .010 \\
\hline 12 mo or less & $106(27.5)$ & & $82(50.6)$ & \\
\hline More than 12 mo & $34(39.0)$ & & $23(77.5)$ & \\
\hline Histology & & .416 & & .089 \\
\hline Nodular sclerosis & $103(32.4)$ & & $72(61.2)$ & \\
\hline Other & $21(24.7)$ & & $19(43.7)$ & \\
\hline Sex & & .650 & & .379 \\
\hline Male & $88(32.6)$ & & $63(59.5)$ & \\
\hline Female & $52(27.7)$ & & $42(55.4)$ & \\
\hline
\end{tabular}

autoSCT indicates autologous transplantation.

"The sum does not add to the total because of missing data. 


\begin{tabular}{|c|c|c|c|c|}
\hline \multirow[b]{2}{*}{ Factor } & \multicolumn{2}{|c|}{ PFS } & \multicolumn{2}{|c|}{ OS } \\
\hline & $\operatorname{HR}(95 \% \mathrm{Cl})$ & $P$ & $\operatorname{HR}(95 \% \mathrm{Cl})$ & $p$ \\
\hline Intention to treatment, no donor versus donor & $1.94(1.38-2.73)$ & $<.001$ & $2.47(1.68-3.64)$ & $<.001$ \\
\hline $\begin{array}{l}\text { Time from autoSCT to relapse, less than } 12 \mathrm{mo} \\
\text { versus more than } 12 \mathrm{mo}\end{array}$ & $1.57(1.06-2.31)$ & .023 & $1.90(1.19-3.01)$ & .007 \\
\hline
\end{tabular}

PFS indicates progression-free survival; $\mathrm{OS}$, overall suvival; $\mathrm{HR}$, hazard ratio; $\mathrm{Cl}$, confidence interval; and autoSCT, autologous transplantation.

\section{Toxicity, Hodgkin-related deaths, and NRM.}

A total of 105 of 185 patients (57\%) died after treatment. The causes of death were disease in 85 patients (46\%), toxicity in 17 patients (9\%), and other causes in 3 patients (2\%).

In the donor group, 56 of 122 patients (46\%) died. Causes of death were the following: disease, $\mathrm{n}=39$ (32\%); toxicity, $\mathrm{n}=15$ (12\%); and other, $\mathrm{n}=2(2 \%)$. In the no-donor group, 49 of 63 patients (78\%) died, 46 (73\%) patients of disease, $2(3 \%)$ of toxicity, and $1(2 \%)$ of other causes. One-year NRM for all the patients was $4.4 \%$.

\section{Outcome of patients receiving allogeneic transplantation}

A total of 104 of 122 patients (85\%) actually proceeded to RIC alloSCT. At the last follow-up, 42 patients (40\%) were alive in CR, whereas 56 of 104 patients (54\%) progressed or relapsed after transplantation. The median PFS was 7 months with an estimated 1 - and 2-year PFS of $41 \%$ and $31 \%$, respectively (Figure $2 \mathrm{~A}$ ). The median OS was 28 months with an estimated 1- and 2-year OS of $69 \%$ and $57 \%$, respectively (Figure 2B). Forty-eight patients (46\%) died, 13 of them without disease progression, and this result translated into a 1- and 2-year NRM of $11.7 \%$ and $12.7 \%$, respectively. Acute and chronic GVHD occurred in $28(27 \%)$ and $37(41.1 \%)$ evaluable patients, respectively. 
A

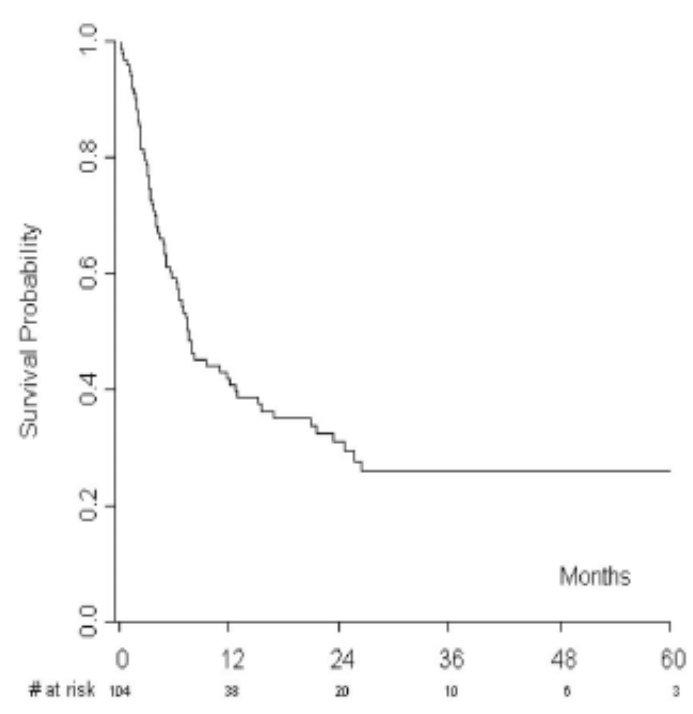

B

os

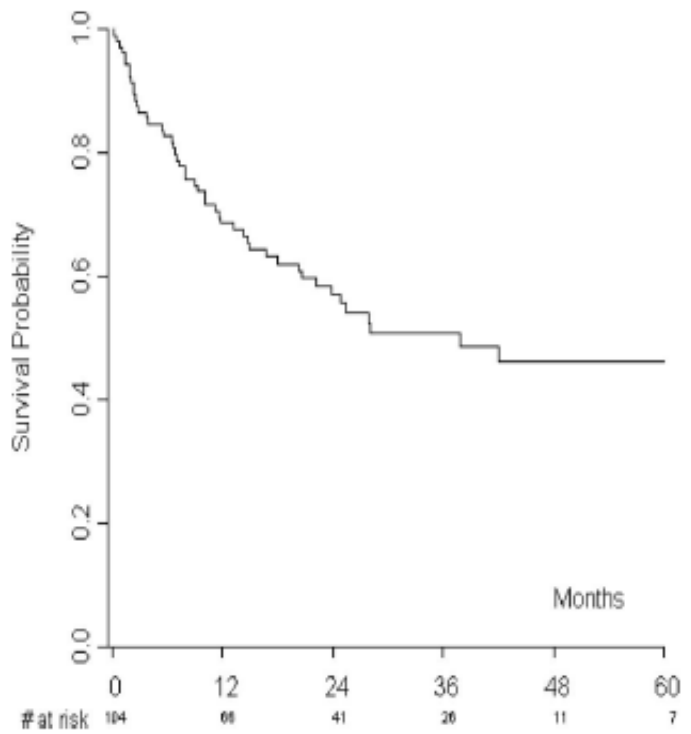

Figure 2. The analysis limited to allografted patients started from the day of allografting. (A) Progression-free survival (PFS) and (B) overall survival (OS) of patients receiving reduced-intensity allogeneic transplantation.

The analysis limited to allografted patients started from the day of allografting. (A) Progression-free survival (PFS) and (B) overall survival (OS) of patients receiving reduced-intensity allogeneic transplantation. We performed a univariate analysis taking into account disease status before alloSCT, the donor type, time from autoSCT to relapse, and the incidence of acute and chronic GVHD (Table 5). The analysis for both OS and PFS showed a significant correlation with disease status before alloSCT $(P \leq .001)$ and the occurrence of GVHD (PFS, $P=.024$; OS, $P<.001$ ) that were included in the Cox model (Table 6).

Table 5. Univariate analysis of allografted patients

\begin{tabular}{|c|c|c|c|c|c|}
\hline \multirow[b]{2}{*}{ Classification } & \multirow[b]{2}{*}{$\mathrm{N}(\%)$} & \multicolumn{2}{|l|}{ PFS } & \multicolumn{2}{|l|}{ os } \\
\hline & & No. (\%) of events (1.5-y survival) & $P$ (log-rank) & No. (\%) of events (1.5-y survival) & $P(\log$-rank) \\
\hline All & $104(100)$ & $70(35.3)$ & & $48(62.0)$ & \\
\hline Status at alloSCT* & & & $<.001 ; .008 \dagger$ & & $.002 ; .074 \dagger$ \\
\hline CR & $21(20.2)$ & $7(65.8)$ & & $4(85.2)$ & \\
\hline PR & $46(44.2)$ & $33(36.1)$ & & $19(61.0)$ & \\
\hline $\mathrm{SD}, \mathrm{PD}$ & $36(34.6)$ & $30(14.1)$ & & $25(48.7)$ & \\
\hline Time from autoSCT to relapse & & & .465 & & .979 \\
\hline 12 mo or less & $75(72.1)$ & $52(34.1)$ & & $34(59.9)$ & \\
\hline More than $12 \mathrm{mo}$ & $29(27.9)$ & $19(38.4)$ & & $14(67.4)$ & \\
\hline Donor type & & & .619 & & .145 \\
\hline Sibling & $57(54.8)$ & $40(33.2)$ & & $23(67.7)$ & \\
\hline Matched unrelated donor & $33(31.7)$ & $21(41.7)$ & & $17(57.1)$ & \\
\hline Haploidentical & $14(13.5)$ & $10(28.6)$ & & $8(50.0)$ & \\
\hline GVHD & & & .024 & & $<.001$ \\
\hline Acute & $28(26.9)$ & $23(21.4)$ & & $18(46.4)$ & \\
\hline Chronic & $37(41.1)$ & $22(53.1)$ & & $9(88.7)$ & \\
\hline № & $39(37.5)$ & $26(27.8)$ & & $21(46.9)$ & \\
\hline
\end{tabular}

PFS indicates progression-free survival; OS, overall survival; alloSCT, allogeneic transplantation; autoSCT, autologous transplantation; CR, complete remission; PR, partial remission; SD, stable disease; PD, progressive disease; and GVHD, graft-versus-host disease.

"The sum does not add to the total because of missing data.

$t P$ value is associated at the comparison for $C R$ versus $P R$. 
Table 6. Multivariable analysis of allografted patients

\begin{tabular}{|c|c|c|c|c|}
\hline \multirow[b]{2}{*}{ Factor } & \multicolumn{2}{|c|}{ PFS } & \multicolumn{2}{|c|}{ os } \\
\hline & HR ( $95 \% \mathrm{Cl})$ & $p$ & $\mathrm{HR}(95 \% \mathrm{Cl})$ & $P$ \\
\hline \multicolumn{5}{|l|}{ Status at alloSCT } \\
\hline PR versus CR & $2.76(1.22-6.25)$ & .015 & $2.96(1.00-8.82)$ & .051 \\
\hline$S D, P D$ versus $C R$ & $5.39(2.33-12.49)$ & $<.001$ & $5.72(1.97-16.56)$ & .001 \\
\hline \multicolumn{5}{|l|}{ GVHD } \\
\hline No versus chronic & $1.68(.93-3.00)$ & .084 & $3.41(1.53-7.58)$ & .003 \\
\hline $\begin{array}{l}\text { Acute versus } \\
\text { chronic }\end{array}$ & $2.51(1.37-4.62)$ & .003 & $4.14(1.85-9.28)$ & $<.001$ \\
\hline
\end{tabular}

PFS indicates progression-free survival; $\mathrm{OS}$, overall survival; $\mathrm{HR}$, hazard ratio; $\mathrm{Cl}$, confidence interval; alloSCT, allogeneic transplantation; $\mathrm{PR}$, partial remission; $\mathrm{CR}$, complete remission; SD, stable disease; PD, progressive disease; and GVHD, graft-versus-host disease.

By multivariable analysis, a significant difference in outcome has been observed comparing patients in PR or in PD/SD versus patients in CR ( $P=.015$ and $P<.001$ for PFS, $P=.051$ and $P=.001$ for OS, respectively). In particular, $\mathrm{HR}$ of disease progression was $2.76(95 \% \mathrm{Cl}, 1.22-6.25)$ for patients in $\mathrm{PR}$ and $5.39(95 \% \mathrm{Cl}$, 2.33-12.49) for patients in SD/PD. Similarly, HR of death for PR and SD/PD patients was $2.96(95 \% \mathrm{Cl}, 1.00$ 8.82 ) and $5.72(95 \% \mathrm{Cl}, 1.97-16.56)$, respectively. Chronic GVHD had a favorable effect on survival compared with acute GVHD or no GVHD. Indeed, HR of patients affected by acute GVHD versus chronic GHVD was 2.51 (95\% Cl, 1.37-4.62) for PFS and 4.14 (95\% Cl, 1.85-9.28) for OS. A different OS was also found comparing no GVHD versus chronic GVHD with an HR of death of 3.41 ( $95 \% \mathrm{Cl}, 1.53-7.58)$ for patients without GVHD.

\section{Discussion}

AlloSCT with RIC regimens has been increasingly used in relapsed patients with promising results in some non-HL subtypes and a less favorable outcome in $\mathrm{HL}^{11,15}$ No prospective randomized studies between RIC alloSCT and salvage chemo-radiotherapy have been conducted in HL patients relapsing after an autoSCT. Only 1 retrospective study by Thomson et al has been published on this topic, showing the superiority of RIC alloSCT over conventional treatment. ${ }^{19}$ Nevertheless, that study has some limitations: (1) less than 40 patients were included in each arm; and (2) only those responding to salvage therapy and surviving more than 12 months were included in the control group.

Our multicenter retrospective analysis tried to overcome these limitations, reporting the results of 185 patients who were considered as potential candidates for RIC alloSCT by their attending physicians. They were divided into 2 groups, named "donor" and "no-donor," and we considered the day of relapse after autoSCT the starting point of our analysis, regardless of whether the patient actually underwent alloSCT or not. In this way, we intended to address 2 issues: (1) to eliminate potentially unknown selection biases between patients undergoing an allograft and those receiving other treatments; and (2) to perform an "intention-to-treat" analysis to evaluate the real clinical impact of a treatment strategy based on donor availability.

Our results clearly showed that the donor group experienced a better OS and PFS with a median follow-up of 48 months, with the majority of events occurring within the first 2 years after post-autoSCT relapse. In univariate and multivariable analysis, the availability of a donor was significant for both PFS and OS, underlying the impact of this factor on outcome. Only a minority of patients $(15 \%)$ in the donor group did not actually proceed to transplantation; and, given the fact that salvage chemotherapy before alloSCT as well as patient characteristics did not differ between groups, we think that the survival advantage can be attributed to the alloSCT. 
To investigate whether the supposed "graft-versus-HL effect" could explain the superiority of alloSCT, we performed univariate and multivariable analysis restricted to allografted patients and including the occurrence of GVHD as the clinical sign of transplantation alloreactivity. In our series, patients with chronic GVHD experienced a better OS and PFS ( $P<.001$ and $P=.024$, respectively) compared with those without it or with acute GVHD. Because HL patients relapsing after an autoSCT have a very poor outcome, we think that the toxicity caused by GVHD can be accepted in view of the survival advantage. Peggs et al were the first to describe the correlation between clinical response and GVHD occurrence after DLI in patients receiving a T cell-depleted RIC alloSCT. ${ }^{13}$ Notably, in their study, CRs were achieved at a median time of 675 days after DLI, suggesting a role for the "graft-versus-HL effect." A recent EBMT analysis on $168 \mathrm{HL}$ patients treated with alloSCT also reported a decreased relapse risk in patients affected by chronic GVHD, which translated into a better PFS without increasing the NRM. ${ }^{12}$

In our study, in both groups the most common cause of treatment failure was disease progression. The NRM did not significantly differ between the donor and the no-donor groups, and this is in line with several previous reports on RIC alloSCT. ${ }^{11-15}$ From a practical viewpoint, this finding supports the feasibility of RIC alloSCT also in heavily pretreated HL patients. In particular, in allografted patients the donor type did not affect toxicity or survival. The Center for International Blood and Marrow Transplant Research described the outcome of the largest group of unrelated donor alloSCT recipients, showing a 2-year PFS and OS of $20 \%$ and $37 \%$, respectively, similar to the ones obtained with sibling donors. ${ }^{26}$ Similarly, the EBMT report on $\mathrm{RIC}$ alloSCT in $\mathrm{HL}$ did not identify the alternative donor as a risk factor for OS. ${ }^{27}$ The Seattle group recently compared the results of nonmyeloablative alloSCT with related, unrelated, or haploidentical donors, and unexpectedly, haploidentical recipients displayed the most favorable outcome, although different conditioning regimens and the limited number of patients could have affected the analysis, as highlighted by the authors. ${ }^{28}$

In our study, the majority of patients received conditioning regimens, including drugs active against lymphoma cells, such as thiotepa or melphalan. When we analyzed the effect of RIC regimens versus nonmyeloablative regimens, such as low-dose total body irradiation or fludarabine/cyclophosphamide, we could not find any difference in terms of outcome, but this might be also attributed to the fact that nonmyeloablative regimens were only $14 \%$ of all conditionings.

In HL, it is well established that chemorefractory patients experience a short survival, as the "graft-versus$\mathrm{HL}$ effect" cannot overcome the aggressive clinical course of the disease. ${ }^{12,14,27}$ Conversely, it is unknown whether the achievement of CR makes a difference compared with the PR status at transplantation. Some studies showed that PR and chemorefractory $\mathrm{HL}$ patients experienced the same outcome, suggesting that only CR before RIC alloSCT should be pursued to allow the immune-mediated effect to be exerted in the long-term. ${ }^{13,17,27}$ In addition, in our study, there was a difference in PFS and OS for CR patients versus PR patients, supporting the notion that pretransplantation CR status is crucial to improve the outcome.

Another known prognostic factor in advanced $\mathrm{HL}$ is the time from autoSCT to relapse because patients relapsing within 12 months are considered a very poor risk category. ${ }^{6,14,29}$ Interestingly, when considering our population, early relapsed patients showed a worse OS and PFS, whereas in allografted patients we did not observe any difference. Although only few patients relapsed after 12 months in our series, this result may suggest that the "graft-versus-HL effect" might overcome the adverse influence of an early relapse.

In conclusion, our retrospective analysis showed that: (1) HL patients relapsing after an autoSCT have a survival advantage if they undergo RIC alloSCT; (2) CR achievement before RIC alloSCT is very important and influences patients' clinical outcome; and (3) NRM after RIC alloSCT is rather low; therefore, this procedure 
can be considered a feasible option in the clinical setting. Finally, we think that prospective clinical trials should address this issue.

\section{References}

1.

Bonfante V,

Santoro A,

Viviani S,

et al

ABVD in the treatment of Hodgkin's disease. Semin Oncol 1992;19 suppl 5:S38-S45.

2.

Schmitz N,

Pfistner B,

Sextro $M$

et al

Aggressive conventional chemotherapy compared with high-dose chemotherapy with autologous haemopoietic stem-cell transplantation for relapsed chemosensitive Hodgkin's disease: a randomised trial. Lancet 2002;359(9323):2065-2071.

3.

Tarella C,

Cuttica A,

Vitolo U,

et al

High-dose sequential chemotherapy and peripheral blood progenitor cell autografting in patients with refractory and/or recurrent Hodgkin lymphoma: a multicenter study of the intergruppo Italiano Linfomi showing prolonged disease free survival in patients treated at first recurrence. Cancer 2003;97(11):27482759.

4.

Vose JM,

Bierman PJ, 
Anderson JR,

et al

Progressive disease after high-dose therapy and autologous transplantation for lymphoid malignancy: clinical course and patient follow-up. Blood 1992;80(8):2142-2148.

5.

Varterasian M,

Ratanatharathorn V,

Uberti JP,

et al

Clinical course and outcome of patients with Hodgkin's disease who progress after autologous transplantation. Leuk Lymphoma 1995;20(1):59-65.

6.

Bolwell BJ,

Kalaycio M,

Goormastic M,

et al

Progressive disease after ABMT for Hodgkin's disease. Bone Marrow Transplant 1997;20(9):761-765.

7.

Little R,

Wittes RE,

Longo DL,

Wilson WH

Vinblastine for recurrent Hodgkin's disease following autologous bone marrow transplant. J Clin Oncol 1998;16(2):584-588.

8.

Shamash J,

Lee SM,

Radford JA, 
et al

Patterns of relapse and subsequent management following high-dose chemotherapy with autologous haematopoietic support in relapsed or refractory Hodgkin's lymphoma: a two centre study. Ann Oncol 2000;11(6):715-719.

9.

Kewalramani T,

Nimer SD,

Zelenetz AD,

et al

Progressive disease following autologous transplantation in patients with chemosensitive relapsed or primary refractory Hodgkin's disease or aggressive non-Hodgkin's lymphoma. Bone Marrow Transplant 2003;32(7):673-679.

10.

Tsai T,

Goodman S,

Saez R,

et al

Allogeneic bone marrow transplantation in patients who relapse after autologous transplantation. Bone Marrow Transplant 1997;20(10):859-863.

11.

Robinson SP,

Goldstone AH,

Mackinnon S,

et al

Chemoresistant or aggressive lymphoma predicts for a poor outcome following reduced-intensity allogeneic progenitor cell transplantation: an analysis from the Lymphoma Working Party of the European Group for Blood and Bone Marrow Transplantation. Blood 2002;100(13):4310-4316.

12.

Sureda $A$,

Robinson S,

Canals C, 
et al

Reduced-intensity conditioning compared with conventional allogeneic stem-cell transplantation in relapsed or refractory Hodgkin's lymphoma: an analysis from the Lymphoma Working Party of the European Group for Blood and Marrow Transplantation. J Clin Oncol 2008;26(3):455-462.

13.

Peggs KS,

Hunter $\mathrm{A}$

Chopra R,

et al

Clinical evidence of a graft-versus-Hodgkin's-lymphoma effect after reduced-intensity allogeneic transplantation. Lancet 2005;365(9475):1934-1941.

14.
Alvarez I,
Sureda A,
Caballero MD,

et al

Nonmyeloablative stem cell transplantation is an effective therapy for refractory or relapsed Hodgkin lymphoma: results of a Spanish prospective cooperative protocol. Biol Blood Marrow Transplant 2006;12(2):172-183.

15.

\author{
Corradini P, \\ Dodero A, \\ Farina L, \\ et al
}

Allogeneic stem cell transplantation following reduced-intensity conditioning can induce durable clinical and molecular remissions in relapsed lymphomas: pre-transplant disease status and histotype heavily influence outcome. Leukemia 2007;21(11):2316-2323. 
16.

\section{Castagna L,}

Sarina B,

Todisco E,

et al

Allogeneic stem cell transplantation compared with chemotherapy for poor-risk Hodgkin lymphoma. Biol Blood Marrow Transplant 2009;15(4):432-438.

17.

Anderlini P,

Saliba R,

Acholonu S,

et al

Fludarabine-melphalan as a preparative regimen for reduced-intensity conditioning allogeneic stem cell transplantation in relapsed and refractory Hodgkin's lymphoma: the updated M.D. Anderson Cancer Center experience. Haematologica 2008;93(2):257-264.

18.

Peggs KS,

Sureda A,

Qian W,

et al

Reduced-intensity conditioning for allogeneic haematopoietic stem cell transplantation in relapsed and refractory Hodgkin lymphoma: impact of alemtuzumab and donor lymphocyte infusions on long-term outcomes. Br J Haematol 2007;139(1):70-80.

19.

Thomson KJ,

Peggs KS,

Smith $\mathrm{P}$,

et al 
Superiority of reduced-intensity allogeneic transplantation over conventional treatment for relapse of Hodgkin's lymphoma following autologous stem cell transplantation. Bone Marrow Transplant 2008;41(9):765-770.

20.
Lamparelli T,
van Lint MT,
Gualandi F,
et al

Alternative donor transplants for patients with advanced hematologic malignancies, conditioned with thiotepa, cyclophosphamide and antithymocyte globulin. Bone Marrow Transplant 2000;26(12):1305-1311.

21.
Dodero A,
Carniti C,
Raganato A,
et al

Haploidentical stem cell transplantation after a reduced-intensity conditioning regimen for the treatment of advanced hematologic malignancies: posttransplantation CD8-depleted donor lymphocyte infusions contribute to improve T-cell recovery. Blood 2009;113(19):4771-4779.

22.

Przepiorka D,

Weisdorf D,

Martin P,

et al

1994 Consensus Conference on Acute GVHD Grading. Bone Marrow Transplant 1995;15(6):825828.

23.

Sullivan KM, 
Shulman HM,

Storb R,

et al

Chronic graft-versus-host disease in 52 patients: adverse natural course and successful treatment with combination immunosuppression. Blood 1981;57(2):267-276.

24.

Labopin M,

lacobelli S

Statistical Guidelines for EBMT. [Accessed April 12, 2007].

http://www.ebmt.org/1whatisebmt/Op_Manual/OPMAN_StatGuidelines_oct2003.pdf.

25.

Gray B

A class of $K$-sample tests for comparing the cumulative incidence of a competing risk. Ann Stat 1988;16:1141-1154.

26.

Devetten MP,

Hari PN,

Carreras J,

et al

Unrelated donor reduced-intensity allogeneic hematopoietic stem cell transplantation for relapsed and refractory Hodgkin lymphoma. Biol Blood Marrow Transplant 2009;15(1):109-117.

Robinson SP,

Sureda A,

Canals C,

et al

Reduced intensity conditioning allogeneic stem cell transplantation for Hodgkin's lymphoma: identification of prognostic factors predicting outcome. Haematologica 2009;94(2):230-238. 
27.

Burroughs LM,

O'Donnell PV,

Sandmaier BM,

et al

Comparison of outcomes of HLA-matched related, unrelated, or HLA-haploidentical related hematopoietic cell transplantation following nonmyeloablative conditioning for relapsed or refractory Hodgkin lymphoma. Biol Blood Marrow Transplant 2008;14(11):1279-1287.

28.

Smith SM,

van Besien K,

Carreras J,

et al

Second autologous stem cell transplantation for relapsed lymphoma after a prior autologous transplant. Biol Blood Marrow Transplant 2008;14(8):904-912. 